\title{
Immune Globulin/Zidovudine
}

National Cancer Institute

\section{Source}

National Cancer Institute. Immune Globulin/Zidovudine. NCI Thesaurus. Code C15479.

A combination of agents containing immune globulin and zidovudine. 